No entanto, ainda se agia de modo restritivo, pois se impedia uma evolução provocada pelas mudanças que pudessem alterar a organização do sistema, por exemplo. Nesse período, o sistema cibernético era compreendido como equivalente a uma máquina trivial ${ }^{3}$, fosse uma máquina, um organismo biológico, um sistema cognitivo ou um sistema social que, tendo uma organização e um propósito, operaria através da correção de desvios, de modo que se mantivesse estável. Estabilidade era, então, sinônimo de sobrevivência. Esse processo de manutenção, pelo qual se considerava que um sistema 'sobrevivia' através de sua constância, era conhecido como 'realimentação negativa'4 É importante destacar o papel da realimentação no processo, onde as informações coletadas eram confrontadas com o padrão de desempenho programado. Dessa forma, a diferença entre o desempenho realizado e o esperado era transformada na informação que o mecanismo de compensação utilizava para trazer o desempenho futuro a valores mais próximos do padrão esperado 5 .

Mas a sobrevivência dos sistemas vivos não depende apenas dess capacidade de se manter estável e constante. Compreendeu-se, então, que além de conseguir manter a estabilidade, um sistema 'vivo' necessitava também ser capaz de modificar sua estrutura básica para adaptar-se às situações de mudanças provocadas pelo meio, ou, ainda, deveria poder contar com a possibilidade de transição para estados de maior complexidade ${ }^{6}$.

Esse novo processo não poderia ser explicado apenas pela 'realimentação negativa', mas, sim, por uma 'realimentação positiva'7, ou seja, mecanismos que amplificariam o desvio de modo que o organismo, adaptando-se às condições de seu contexto, conseguiria sobreviver às 'intempéries ambientais' Esses processos de amplificação do desvio, e os processos sistêmicos de mudanças daí decorrentes, foram descritos como um próximo passo dado pela cibernética, constituindo-se assim no seu segundo momento ${ }^{8}$.

Mas o diferencial entre a cibernética de primeira e a de segunda ordem é seu posicionamento diante do observador do sistema. Além da preocupação com a 'realimentação positiva e negativa', um sistema pode ser operado 'de fora', entendendo-se dessa forma que seus modelos formam uma realidade independente do observador. Ou seja, o observador não faz parte do contexto, ou, ainda, não é levado em consideração pelo sistema. E este seria o outro princípio importante da cibernética: enquanto a cibernética de primeira ordem não ncluía a idéia de auto-referência (e estenda-se que um observador de fora não participaria do sistema), caracterizada pelo postulado da independência entre observador do sistema e sistema observado, na segunda cibernética, pelo contrário, nasce a idéia de auto-referência (tanto do sistema em si e suas unidades formadoras quanto do observador que dele participa), e aqui o observador faz parte da observação. Instauradas a auto-referência e a participacão do observador, a relação entre os elementos do sistema ganha novo status.

Dessa forma, enquanto a primeira cibernética se interrogava sobre as noções de controle e de comunicação da informação (entre animais, indivíduos e máquinas), a segunda cibernética interroga-se sobre as noções de auto-organização, estruturas emergentes, redes, adaptação e evolução, termos decorrentes dos fatores relacionais entre os elementos internos (endógenos) e externos (exógenos) do sistema ${ }^{9}$

A segunda cibernética é, então, um movimento considerado como a cibernética dos sistemas auto-observantes (também chamados de "sistemas que observam”). A segunda cibernética foi uma evolução, relacionada com um extensão do conceito de circularidade. Todo observador, ao observar un sistema, distingue-o como tal, constrói-o e forma com ele outro sistema do qual participa. Liga duas realidades antes separadas, funcionando como se fossem uma só. O sistema garante ainda sua individualidade, pois em si é uma unidade que possui capacidade auto-organizativa. Ao surgir uma perturbação, tem capacidade de alterar a sua estrutura, mantendo o seu equilíbrio. O funcionamento dos sistemas é, portanto, e de certa forma, autônomo. Autonomia aqui se refere a um estado de auto-regulação que proporciona ao sistema estabilidade e equilíbrio, de maneira que este, ao reagir às perturbações externas, se possa reestruturar e compensar alguns desvios decorrentes. Ainda estamo tratando de uma condicão determinista e mecânica, não levando em conta processos de crescimento, aprendizagem, criatividade e autopoiesis.

Os biólogos Humberto Maturana e Francisco Varela ${ }^{10}$ deram impo tante contribuição para a implementação desse processo. O Modelo Autopoiético de Maturana e Varela faz a distinção entre sistemas alo autopoiéticos, ampliando a idéia da auto-organização dos sistemas, onde um sistema vivo é caracterizado por uma organização circular, auto-referencial, que literalmente se autoproduz a si mesma. O termo 'autopoiesis' é usado para evidenciar esse tipo de autonomia de um sistema com autocontrole. Quando o controle vem de algum outro lugar, de seu exterior, o sistema é 'alopoiético' Entretanto, pleno autocontrole e ação autônoma são conseguidos apena através de outra capacidade: a de 'auto-referencialidade'. Nas palavras de Winfried Nöth: "A auto-referência é uma necessidade biológica para seres vivos uma vez que o organismo, para sobreviver no seu ambiente, deve ter a capacidade de distinguir entre seu próprio self e o não-self da Unwelt ambiental"11.

Partindo desse princípio, para cada perturbação do exterior o sistema reage reestruturando-se e compensando-se, o que significa que, devido ao se caráter autônomo, sua auto-referencialidade e suas tomadas de decisão (e independência), nenhum fator ou observador externo sabe ao certo o que acontecerá a seguir.

Outro nome a ser lembrado neste momento é o de Ilya Prigogine ${ }^{12}$. A teoria da equilibração dos sistemas termodinâmicos, apresentada por ele, refere-se às perturbações a que um sistema está sujeito. Estas "pequena mudanças" permanentes que, ao atingirem determinado estado "longe do equilíbrio", originam um salto qualitativo no sentido de estabelecer uma nova estrutura, ou seja, na passagem de um modo de funcionamento a outro sofrem uma transformação (uma amplificação).
Ou seja, refere-se a qualquer processo por meio do qual uma ação é controlada pelo conhecimento do efeito de suas respostas. Introduz-se aqui a idéia de looping, onde um fluxo de informação retorna à sua origem, um processo circular causal no qual uma saida de dados do sistema produz efeitos que retornam à sua entrada, possivelmente envolvendo outros sistemas em looping também. A chave está em como os efeitos de suas ações (ou saídas de informação) retornam ao sistema (isto é, às entrada de informação) para influenciar seus estados e acõos subsequientes - $a$ isso denominamos de real mentacão ou feedback reslimenter negativa privilegiam-s os prosios de correçãa dos desvios dos siste

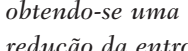
redução da entropia

WIENER. Op. cit., p. 24.

6. Heinz Von Foerster leve ser lembrado neste nomento, pois apresenta, em 1959, no colóquio "Os princípios da auto-organização", a idéia de que não hă sistemas auto-organizadores isolados de sen meio e de que haveria necessidade de um observador que pudesse constatar se essa autoorganização realment estava ocorrendo. 
As influências do meio a figura do observad começam a participa do sistema. Entretanto, para Wiener: "uma ação complexa é aquela en que os dados introduzidos (a que chamamos de entrada) para obter un efeito sobre o mundo exterior - efeito a que chamamos de saída podem implicar un grande número de con binações. Combinaç̃ós dos dados introduzidos

no momento com registros obtidos de dados anteriores armazenados, a que chamamos memória e que estão registrado

na máquina".

Na realimentacão positiva

os processos de ampliação do desvio

incrementando

entropia e amplificando

o sistema.

8. Na verdade, contamos aqui com três teoria fundadoras: cibernétic (primeira cibernética) e teoria dos sistemas.

9. Veja Edmond Couchot e se conceilo de Segund Interatividade, que fo sugerido por analogi à segunda cibernétic

...que coloca em jogo comportamentos maquinicos mais complexos e refinado próximos dos comporta mentos humanos... COUCHOT, Edmond. segunda interatividade.

Em direção a nova práticas artísticas.
Os fatores de imprevisibilidade, acaso e irreversibilidade são introduzidos no processo dessa mudança, uma vez que a nova estrutura não é predeterminada e está sujeita às contingências atuais, sendo impossível regressar ao estado anterior. Outro conceito importante é o de estruturas dissipativas, também introduzido por Prigogine para descrever um sistema aberto, em estado de quase equilíbrio, e a sua capacidade para criar uma nova estrutura auto-organizada, a partir de amplificações das suas próprias flutuações. E, para melhor compreensão desses fenômenos, Prigogine introduziu a noção de 'retroação evolutiva', que completa o quadro das 'realimentações negativa e positiva', procurando explicar os mecanismos de 'mudança descontínua'.

Sendo assim, o funcionamento dos sistemas depois das mudanças atingidas será não só imprevisível como também irreversível: nunca sabemos para que tipo de funcionamento evoluirá (perdemos a capacidade de previsibilidade) e o sistema nunca volta a um estado de funcionamento anterior progredindo para estados de funcionamento cada vez mais complexos.

Todo este percurso demonstra um pensamento que está infiltrado no nosso cotidiano, e basta pensarmos em como movimentamos dinheiro no banco, acessamos a Internet, dirigimos um carro, ou, mesmo, como mantemos um convívio social, para percebermos estes processos de raciocínio derivado de controle, manutenção, sistema, interatividade, banco de dados, variáveis, reversibilidade, conectividade, recursividade, mutabilidade, acaso, redes, padrões emergentes, perspectivas múltiplas... Apresentaremos a seguir uma apropriação de alguns desses princípios pela arte, mais especificamente, pela poesia digital.

\section{0 contexto}

A pesquisa sobre 'escrituras digitais' inicia-se com a poética das combinações permutacionais e culmina com sistemas dinâmicos e complexos, autônomos, multiusuários e interativos, através de derivações da geração de agentes, filtragem e padrões emergentes, e demonstra uma estreita relação entre a poética (no sentido de 'programa de arte'13) e os algoritmos.

Tratar de matemática e lógica computacional em poemas quase que imediatamente nos remete à 'Poesia Permutacional' dos anos 1960, de Théo Lutz (Alemanha), Jean Baudot (Canadá), Nanny Balestrini (Itália). Além disso, relembrando as palavras de Arlindo Machado, o sonho de Mallarmé14 era dar forma a um livro integral, "...ou talvez uma máquina poética, que fizesse proliferar poemas inumeráveis; ou ainda um gerador de textos, impulsionado por um movimento próprio, no qual palavras e frases pudessem emergir, aglutinarse, combinar-se em arranjos precisos, para depois desfazer-se, atomizar-se em busca de novas combinações" 15

Já naquele momento, há mais de dez anos, Machado apontava inovações estéticas que conduziriam para uma 'obra potencial', mais do que uma 'obra aberta' ou 'polissêmica', pois agora os “...poemas estariam em estado latente em que, a partir de um reduzido número de células de base, se poderia realizar milhares de possibilidades combinatórias"16.

E, embora Mallarmé não tivesse condições técnicas para realizar seu sonho naquele momento - pois não tinha os meios para realizá-lo -, ele acabo esboçando um conceito de 'poema-constelação', através de seu trabalho "Lance de Dados" (1897), que, mesmo que ainda se sustente por um suporte linear e hierarquizante, traz novos parâmetros para a "...gramática, a sintaxe, a disposição gráfica, o sentido e a própria razão de ser do poema" 17 .

Além de 'obra potencial' e de 'poema-constelação', devemos lembrar também da 'poesia artificial' de Max Bense ${ }^{18}$, que seria o resultado de uma poesia em que se buscava, com a mediação de processos tecnológicos, da solução estatística, estrutural ou topológica a parâmetros textuais gerados pela máquina, opondo-se à 'poesia natural', que exprimiria uma experiência global, através de vivência, sentimentos, lembranças, imaginação ${ }^{19}$. Um dos processo básicos para se gerar um texto "artificial" é dado por uma série estocástica ou probabilística conhecida como cadeia de Markov.

Tal processo baseia-se na idéia de que todo texto é construído operando-se uma seleção de sinais (fonemas e letras) numa determinada fonte (alfabeto fonético ou escritural), segundo certas regras de combinação previamente dadas pelo estudo estatístico de uma língua. A abordagem seletiva executa essa operação através de etapas ou graus de aproximação. Numa primeira etapa, o texto é gerado com base na freqüência relativa de cada letra ou fonema naquela língua, com espaços intervalares arbitrários, porém cabíveis para o idioma dado. O resultado é um texto que exprime certas propriedades estatísticas da língua, mas que ainda não apresenta qualquer semelhança perceptível com o seu repertório léxico. Num segundo grau de aproximação, condicionamos o aparecimento de uma letra ou fonema à ocorrência de determinados outros sinais precedentes ou sucessores, que já elimina boa parte das combinações inaceitáveis (em português, por exemplo, jamais teríamo digramas como 'pfr', 'mr', 'jt' etc.). Se, em vez de condicionarmos um sinal à ocorrência de algun outros tomados isoladamente, nós o fizermos levando em consideração grupos de duas letras ou fonemas, as possibilidades de ocorrências inaceitáveis serão drasticamente reduzidas e o texto resultante se aproximará bastante da língua utilizada como modelo. Com grupos de três letras ou fonemas, já se pode simular o idioma com bastante exatidão, dada a grande quantidade de palavras que se torna identificáveis como portadores de sentido. Prosseguindo o processo, poderíamos passar a grupos de palavras ou a frases inteiras, de modo a gerar textos aleatórios e experimentais, baseados na possibilidades combinatórias de uma língua. 20

Processos estocásticos ${ }^{21}$ são modelos que evoluem no tempo de maneira probabilística. Uma cadeia de Markov é um tipo de processo estocástico, que trabalha com estados discretos, ou seja, sobre um conjunt enumerável ou finito. A probabilidade condicional de qualquer evento futuro ocorrer, dados qualquer evento passado e o estado presente, será independente do evento passado e dependente somente do estado presente. Em outra palavras: um processo estocástico é dito ser um processo markoviano se o estado futuro depende apenas do estado presente e não dos estados passados. Esse tipo de processo estocástico é também denominado de 'memoryless process' (processo sem memória), uma vez que o passado é 'esquecido' (desprezado) ${ }^{22}$
In: DOMINGUES, Diana (Org.). Arte e vida no séc XXI. São Paulo: UNESP, 2003, p. 27-38.

O. MATURANA, Humberto; VARELA, Francisco. Autopoiesi realization of the living. Boston: D. Reidel Publishing Company, 1980

11. NÖTH, Winfried. Máquinas semióticas. Galáxia - Revista Transdisciplinar de Comunicacão, Semiótica, Cultur São Paulo: EDUC, 2001, p. 67.

2. PRIGOGINE, Ilya; STENGER, Isabelle. Oronto: Bantam, 198

13. Toda atividade artística necessita de ma poética, implícita o explícita, que reflete elou aponta para um . Le uma época, de forma arressa ou não na obra de arte. Luigi Pareyso Os Problemas da Estetica. (1984). São Paulo: Martins Fontes, 2001, p. 17.] definir que a poética
é um determinado gosto convertido em progra de arte, levando em conta o caráter programático e operativo da obra.

14. Nascido em Paris em 1842, o poeta Stéphane Mallarme (nome literário de Etienne Mallarmé) possui o poema experimental "Un Coup 
16. Idem, ibidem

17. Idem, p. 166

18. BENSE, Max.

Pequena Estética. São Paulo: Perspectiva 1971, p. 181-197.

19. MACHADO. Op cit., p. 171. Apesar
Um exemplo bastante comum era o exercício realizado através de um dicionário memorizado com uma lista suficientemente extensa de palavras de uma língua, arquivada numa memória de máquina, e onde se aplicava grande parte dos procedimentos oulipanos ${ }^{23}$, que podem ser automatizados, cabendo ao poeta programar aqueles efeitos que queria obter. O computador é capaz de varrer em alta velocidade as palavras do dicionário e selecionar todas aquelas que cumprem determinadas condições previamente colocadas pelo artista.

Entre os diferentes métodos adotados dentro dos procedimentos oulipanos encontramos:

1. palavras de um texto escolhido eram substituídas por suas definições de dicionário; 2 . através do cruzamento entre provérbios, utilizando a primeira parte de um e a segunda parte do outro e vice-versa, eles se reelaborariam, o que poderia ser interessante pois os provérbios podem ser interpretados como narrativas em si mesmos; 3. a retirada de uma letra (a letra ' $r$ ' por exemplo) de um texto; 4 . a redundância poética de alguns textos poderia ser reduzida a poucas palavras de sua essência, enquanto o resto poderia ser descartado; 5. univocalismo, onde apenas uma vogal seria usada no texto; 6 . uma ou mais letras seriam excluídas de um texto. Um exemplo é o romance de Georges Perec A Void 24 , onde nenhuma vogal "e" (aparentemente a letra mais utilizada em uma língua) aparece (esse é um exemplo de lipograma); 7. talvez o procedimento mais conhecido utilizado pelo grupo seja o denominado " $\mathrm{n}+$ 7". Inventado por Jean Lescure, consistia em substituir cada nome $(\mathrm{N})$ pelo sétimo nome seguinte à sua posição em um dicionário. Assim, escolhido um texto e um dicionário, identificam-se os nomes no texto e substitui-se cada um pelo sétimo nome (contando a partir dele) encontrado no dicionário; etc. ${ }^{25}$.

Também merecedor de destaque é o trabalho "Cent Mille Milliards de Poèmes” de Raymond Queneau (1961). A obra consiste basicamente em dez sonetos de catorze versos alexandrinos, portanto dez sonetos-padrão. Os versos são impressos numa 'cinta de cartão' e podem ser destacáveis por uma das pontas, para com eles se construir outros sonetos. Embaralhando os versos de todos os sonetos, o leitor pode compor nada menos que $10^{14}$, ou seja 100.000.000.000.000 poemas diferentes. Cada linha é uma unidade isolada, que pode ser permutada com qualquer outra linha de quaisquer dos 10 sonetos e, seja qual for o arranjo, a peça resultante estará sempre gramatical, estilística e semanticamente realizada. "É uma espécie de máquina de fabricar versos" - explica Queneau ${ }^{26}$. "A poesia dela resultante poderia ser chamada de exponencial, pois o número de poemas de $\mathrm{n}$ versos que se pode obter é dado pela função exponencial de 10n"27. Nesse exemplo, a função da fruição coerente da obra está a cargo do leitor, que compõe e lê o poema.

O programa "Computerized Haiku", de Margaret Masterman e Robin McKinnon-Wood, era considerado 'uma máquina de escrever poemas' e incluía um 'frame' ou 'modelo' e uma 'enciclopédia estruturada'. O modelo era a forma fixa do poema. O sistema processava por substituição (método diferente das cadeias de Markov ou de 'gramáticas recursivas') e seu mérito era a tentativa de manter um esquema semântico - na forma de um diagrama - nos poemas gerados a partir da colaboração de participantes. Esse trabalho participou de uma importante exposição de arte por computador (muitos reconhecem como a primeira), "Cybernetic Serendipity", realizada em Londres, em 1968

Ainda, entre os pioneiros, em 1965, Emmet Williams (EUA) usa as 101 palavras mais utilizadas por Dante na Divina Comédia para criar um poema computacional. As séries de diagramas (e intergramas) de Jim Rosenberg também devem ser citadas, algumas publicadas pela Eastgate Systems, outra impressas ou distribuídas via Internet desde 1979.

Não podemos deixar também de mencionar o trabalho de Christian Bök, "Eunoia" (2001), um lipograma univocal, onde cada capítulo se restringe a usar apenas uma vogal. Assim temos o capítulo "A", o capítulo "E", o capítulo "I", o capítulo "O" e o capítulo "U". Nessa obra percebe-se claramente a intervenção do autor no processo, motivo pelo qual se mantém a sua coerência semântica.

E, entre os brasileiros, devemos lembrar de Erthos Albino de Souza sua obra "Le Tombeau de Mallarmé" (1972), que aplicava modelos conceituais matemáticos ou físicos à construção e/ou desconstrução de textos; e Waldemar Cordeiro com seu trabalho "Beabá" (1986), programa que gerava 'palavras' ao acaso a partir de um sorteio de conjuntos de letras de vários comprimentos (i.e. conjuntos de cinco letras); entre outros 28

A maior crítica lançada aos textos produzidos pelo computador por processos permutacionais, através de séries estocástica ou probabilística, equações randômicas, fractais ou outro procedimento matemático, é que eles não constituem mensagens comunicativas em si, “...não exprimem idéias ou sentimentos de um sujeito enunciador, nem relatam fatos de uma imaginação. A diferença está na imensa dificuldade de se formalizar e traduzir em linguagem de máquina considerações de ordem semântica"29. O que, conseqüentemente, flagra a deficiência de se parametrizar questões semânticas através de modelos lógicos.

Claudia Giannetti aponta também o fato de nesses trabalhos “...não se levar em conta os sujeitos que participam no processo de comunicação, nem o contexto no qual se dá, nem seus valores semânticos". Além disso, "a estética informacional valoriza aquilo que é quantificável, ou seja, restringe-se somente a estruturas sintáticas, o que resulta na limitação da informação a um níve superficial e restrito". Conforme Giannetti, "a tentativa de encontrar um medida' estética baseada na informação está destinada ao fracasso, uma vez que parte do pressuposto da existência de um significado imanente na obra de arte, isto é, independente do observador e do contexto" ${ }^{30}$. Ela ainda é mais radical quando conclui que

a idéia de um significado 'em si', unicamente sintático, contradiz o próprio sentido de comunicação, uma vez que a informação isolada (o sinal) não contém nenhum valor cognitivo. É somente por meio da comunicação, entendida como intercâmbio dialógico entre sujeitos ou como conexão entre estruturas, que a informação pode chegar a assumir um sentido estético. ${ }^{3}$

Laurentiz $\quad 1$ o poder da memória e das ações ali passadas. Veja próxima nota.

22. Como pudemos perceber na introdução dos princípios cibernéticos, os mecanismo de realimentação do sistema (feedback positivo e negativo) modificam esse processo, pois não desprezam os dados recolhidos anteriormente, o que irá modificar bastante as iniciativas dos trabalhos mais recentes.

23. OULIPO é um grupo (fundado na França em 1960) que se propõe a desenvolver uma literatura potencial. Entre seus membros estão escritores bros estão escritores quais destacamos: Raymond Quenea Francois Queneau, Clançois Le Lionnais, Perec Berge, Georges

24. A Void foi a traducão americana do lipograma La Disparis

25. Veja mais informações em http://www.oulipo.net/. 26. OULIPO. L Littérature Potentielle. Paris: Gallimard, 1973, p. 243

27. MACHADO Op. cit., p. 179.

28. Estamos realizando uma vasta pesquisa sobre os artistas brasileiros que atuam nessa área e estaremo apresentando os resultados em outra publicação. 


\section{Algumas propostas atendendo às críticas}

O que podemos fazer para contornar esses problemas são algumas condutas no processo criativo, como, por exemplo:

2.1. Submeter textos 'naturais' ao trabalho estocástico do computador, de "...modo a revelar processos causais não esperados. Assim, significados prefixados sofrem a ação desreguladora dos métodos aleatórios e se beneficiam da singular dialética que põe em jogo o programa, a possibilidade e o acaso, o sentido e a desordem"32. Dessa forma, do ponto de vista semântico, a máquina produziria resultados que, embora possam parecer desconcertantes, seriam válidos.

2.2. Uma outra maneira de escapar ao automatismo da máquina seria permitir alguma ação criativa expressiva ao autor no interior do procedimento dado. Por exemplo, dois ou mais poemas preexistentes seriam tratados como um inventário de palavras (um banco de dados) e, depois, o poeta faria suas intersecções, destacaria palavras comuns, substituiria elementos por outros, e continuaria, assim, construindo a partir de critérios pessoais o seu poema...

2.3. Nesse sentido, também podemos trabalhar hoje em dia explorando cada vez mais as interfaces e formas de participação e interação do leitor/interator. Concedendo, assim, ao leitor da obra sua fruição/criação; além de propiciar novos desafios e experiências a partir do uso de diferentes dispositivos e modos de representação. Lembremos ainda que o desenvolvimento de dispositivos de hardware e software atualmente possibilita gerenciar e processar informações complexas. Podemos reconhecer padrões (escritos ou falados, por exemplo), re/produzi-los sinteticamente, transmutá-los em novos sinais etc.

2.4. Não apenas devemos aprender cálculos matemáticos, mas nos inspirar nos conceitos lógicos que eles carregam em si. Em outras palavras, interessa menos o que se pode selecionar ou substituir em um banco de palavras, causando todo tipo de peripécia mirabolante (ou a supervalorização do quantificável), e mais o efeito que um conceito pode estar causando na linguagem. Por exemplo, o que as idéias de duração e infinito, imprevisibilidade, aleatoriedade, probabilidade trazem à tona, e como passam a mudar nosso comportamento a partir do momento em que convivemos com elas na era digital.

2.5. E, por último, a partir das relações possíveis entre assuntos de outras áreas, podemos obter resultados surpreendentes através da maneira como iremos absorvê-los na imagem e nos processos sígnicos. Por exemplo, a questão dos sistemas complexos, advinda da física, sendo explorada poeticamente em ambientes interativos, e assim por diante.

A seguir apresentaremos quatro exemplos de trabalhos que utilizam alguns mecanismos introduzidos pela cibernética e pela noção de sistema na poesia digital. Não se trata de um discurso da técnica ou de uma visão ideológica sobre a dominação científica... Antes disso, nós consideramos necessário procurar desdobramentos estéticos da tecnologia, pois acreditamos que o fazer poético perpassa os fatores da linguagem e, portanto, da técnica.
Os trabalhos que apresentaremos não representam os domínios totais da cibernética, alguns utilizam apenas poucos de seus recursos. Tampouco pretendemos encerrar as questões da poesia digital com estes exemplos.

\section{3. "Percorrendo Escrituras" 33 através de 4 projetos}

\section{1. "For All Seasons" (2004)}

http://www.hahakid.net/forallseasons/forallseasons.html

Este é um trabalho sobre memória, estações do ano e uso da linguagem textual, recuperando resquícios de lembranças que, em decorrência deles, gerariam uma nova proposta poética e interativa. Inicialmente, deparamo-nos com uma página branca, com um texto em preto, onde são descritas situações que remetem a memórias de sua autora. A seguir somos transportados para um outro ambiente, agora tridimensional, onde leis físicas passam a representar as estaç̃̃es do ano a que se referem as memórias lidas. $\mathrm{O}$ leitor pode mover-se e agir sobre os elementos desse ambiente; pode pausar a simulação física que está acontecendo diante de seus olhos; pode retornar a qualquer outra página - ou estação do ano. Por exemplo, em "outono", podemos parar um vendaval e mover as letras que o compõem. Em "Verão", as letras e palavras comportam-se como se fossem organismos vivos 'nadando' em águas calmas. O leitor pode, entretanto, movimentar e desorientar esse estado. Mas, depois de alguns segundos, o ambiente recupera seu controle e volta a se estabelecer como um ambiente controlado e ordenado. Cada um dos ambientes remete a uma estação do ano, a memórias descritas inicialmente e a uma simulação a partir de agentes e comportamentos físicos. Em "Primavera", 'dentesde-leão' florescem e o toque do leitor faz as sementes se soltarem e dançarem na tela do computador, como se fossem pegas pelo vento. E em "Inverno" podemos ler as seguintes inscrições iniciais:

I've never been very good at drawing, which means that I can easily remember the few drawings I've made where I've really enjoyed the results. I remember this particular one I made during art class in school when I was about 15 years old. The drawing was very simple and couldn't have taken me the entire hour to make. It was a brown tree drawn on black paper, the branches covered in white snow, all in crayon. It wasn't the Mona Lisa, but I really liked it. It captured the feeling of a quiet, dark winter morning, which was what I was seeing when I looked out the window. Unfortunately I don't have the drawing itself anymore, but I do have the memory. And now I have this.

De repente, as letras do poema transformam-se em flocos de neve, que pousam nos galhos secos de uma árvore marrom, sobre um fundo preto. A autora relata uma experiência adquirida aos 15 anos. Uma sensação que um desenho lhe tenha passado sobre o exato sentimento de uma manhã escura de inverno, fria e quieta. O desenho de uma árvore marrom sobre preto com galhos cobertos por neve está aqui representado em movimento, é dinâmico, através de comportamentos simulados e com propriedades interativas. Cada ambiente simula ações de objetos (comportamentos) regidos por leis físicas. Cada
33. O projeto vem sendo desenvolvido no Departamento de Artes
Plásticas da ECA-USP. Clasticas da ECA-USP. Em linhas gerais, preten estruturas da informacão Jigital que comprmação ligital que compartilham a condicão estética. condição estética.

objetivo é procurar, Chtre as funçōes algorítmicas e outras propriedades especificas do computado quais as suas possibilidades expressivas. Trata-se e projeto teórico e práti co, interdisciplinar, onde a partir do estudo do processo evolutivo da linguagem de programação, da lógica e da matemática são realizadas experimentações poéticas decorrentes. 
movimento é regido por um algoritmo e por isso adquire a capacidade de retornar ao equilíbrio após uma ação do usuário que o tenha desestabilizado.

A idéia, conforme a autora, Andreas Müller, era usar elementos interativos para ajudar a comunicar melhor aquilo que transcrevia de suas memórias usando apenas palavras. Os elementos interativos propiciados pela implementação dos comportamentos lançavam novas experiências e desafios aos poemas. Trata-se de um sistema fechado, mas que se torna imprevisível diante das movimentações do usuário/leitor/interator.

\section{2. "Exquisite Copse" (2005)}

\section{(http://www.devoid.co.uk/exquisitecopse/) ${ }^{34}$}

Num jogo surrealista, "Exquisite Copse" reescreve, visualmente, trabalhos existentes da literatura, em uma floresta de árvores de palavras, baseada em palavras seminais digitadas pelos visitantes. Cada galho, que cresce a partir de palavras, segue o texto e o contexto original. As árvores colecionadas formam uma paisagem surrealista e propiciam uma jornada por miríade de narrativas, criadas e influenciadas por ambos: o visitante e o autor procedimental da obra.

O autor remete à idéia de árvore, mas não apenas aquelas do tipo orgânico, aquelas fora de nossas janelas, mas também aquelas em nossas mentes, aquelas que nós costumamos usar para filtrar informações de nossas vidas, no entrelaçar de nossos pensamentos. $\mathrm{O}$ autor, Neil Jenkins, um artista britânico, tece esses emaranhados de palavras como se fossem jogos de trocadilhos. Ele cita um jogo, por exemplo: tome um pedaço de papel; desenhe ou escreva nele; dobre de forma que a pessoa próxima a você não possa ver o que você escreveu/desenhou; passe-o para a próxima pessoa de uma rede/fila e assista um poema/imagem evoluir desse processo... "Exquisite Copse" se inspira nesses envolvimentos, convida visitantes tanto a visualizar árvores que já foram começadas por visitas anteriores, como a plantar uma nova árvore.

Os usuários podem controlar o crescimento visual de suas árvores com o clique do mouse - como se, em vez de 'pay-per-click', fosse um 'rain-per-click' ou 'water-per-click', (fazendo chover a cada clique do mouse). Uma seleção de romances forma o banco de dados em que "Exquisite Copse" trabalha. Existem entre seus textos desde a Metamorfose de Kafka, Moby Dick, Carroll, em Alice no País das Maravilhas; até textos de Douglas Adams e Samuel Beckett. Os usuários semeiam essas árvores textuais a partir de suas próprias palavras. As palavras dos usuários que forem sendo encontradas nos textos originais (seleciona-se um dos textos logo no início do programa) fazem surgir os galhos de uma nova árvore, e assim sucessivamente. As entradas dos usuários (palavras digitadas) e os cliques locais do mouse orientam o crescimento dos galhos das árvores. É um sistema onde os elementos internos mantêm relações entre si e, ainda, permitem a participação de um agente externo. O controle para se manter a coerência e estabilidade do programa está entre as regras que gerenciam toda a evolução do sistema, embora não estejam explícitas as utilizações desses recursos visualmente. Ainda que sejam imprevisíveis as palavras digitadas pelo usuário/interator e seus locais de clique do mouse, o sistema atua sobre um banco de dados fechado e não há forma par ampliação estrutural desse processo.

\section{3. "The Jabberwocky Engine" (2001)}

(http://epc.buffalo.edu/authors/hennessey/data/jabber/index.html)

O programa "The Jabberwocky Engine" 35 produz palavras aparentemente sem sentido, mas que se parecem com palavras inglesas 'regulares' Quando uma letra entra em contato com outra letra, ou grupo de letras, un cálculo ocorre para determinar se elas estatisticamente se pareceriam com proximidade léxica da língua (inglesa, no caso). Surgem então novos agrupamentos de letras que se acumulam para formar palavras que vão resultar em um poema dinâmico, que flutua na tela a partir de cada reavaliação do gerador do sistema. Há uma analogia entre letras e átomos, palavras e moléculas, nessa 'química lingüística' realizada pelo programa de Neil Hennessy. Essa aproximação com a química também está explícita na aparência gráfica da tela: lembra-nos fórmulas químicas mais do que poemas... Essa estética árida e acética nos provoca novas relações poéticas também. Além disso, o programa utiliza as cores azuis para representar palavras que são fragmentos ou palavras inteiras; verdes para palavras formadas pela composição de duas azuis; vermelhas para restos de palavras que explodirão nesse balé léxico. É irônico, surpreendent e o programa nos oferece, ainda, a possibilidade de abrir uma janela ond teremos uma lista das novas palavras criadas, que vão surgindo pelos procedimentos interativos $^{36}$

\section{4. "Community of Words" (2005) 37}

(www.e-gallery.com.br/cp/)

"Community of Words" é um sistema multiusuário que se process através de um ambiente onde o participante é convidado a escrever linearmente seu poema, e de um ambiente tridimensional interativo onde o participant pode observar, navegar e transformar este mesmo poema com os demai participantes do sistema, simultaneamente. Um programa registra as entradas do usuário num banco de dados, filtra algumas condições preestabelecidas e depois procura por palavras repetidas que lhe garantirão maior fator de permanência no sistema (adaptabilidade). Em seguida, há uma procura por seqüências de três e de quatro letras iguais encontradas nas demais palavra enviadas. Esse processo procura encontrar semelhanças formais entre as palavras. Essas semelhanças já carregam relações fonéticas - pois o som é parecido -, gráficas e alguma relação indicial, que em muitos casos são dadas por famílias de palavras, ou palavras cognatas ${ }^{38}$. Num segundo momento, passa-se por um estágio onde cada palavra do sistema se relaciona entre si, ora disputando um mesmo espaço, ora permanecendo próxima de suas correlatas e or desaparecendo do ambiente. Há ainda um fator relacional entre palavras que
35. Inspirado em Carroll.
36. Seria interessante citar o projeto

"Andarilho", do grupo DDVILA. Já descreveoutra publicacão LLAURENTIZ Silvia. Processos computaProcessos computare. . 1, n. 2. São Paulo Departamento de Artes 2003, p. 45-55.], ape nas reforçariamos que este tambem era um programa que criava novas palavras a partir a troca entre prefixo sufixos de palavras originais de um banco de dados. A proposta cra outra, mas o proces so era alimentado por um algoritmo genético a participação dos 
37. Esse projeto foi inicialmente idealizado por

Silvia Laurentiz e

2004 e teve a colabo-

ração de Luciano

Gabriel. Em 2005 foi

implementada sua fas

final com a co-autoria de

Silvia Laurentiz

Martha Gabriel. Faz

parte do projeto de
pesquisa "Percorrend

pesquisa "Percorrendo
Escrituras", já apresento-

do anteriormente.

38. Veja o Projet "Thinkmap Visuc Thesaurus", disponive em: http://www.visu-
althesaurus.com/?vt. forem mais de uma vez enviadas juntas, em poemas de diferentes usuários enotando uma relação semântica de alguma espécie ${ }^{39}$. Logo após o usuário ter escrito seu poema na tela ele se torna parte do banco de dados e suas palavras começam a se posicionar no espaço tridimensional, relacionando-se com as demais palavras (algumas, inclusive, desaparecendo). Assim, cargas sensórias e cognitivas estariam participando e gerariam reflexos que poderão ser novamente experienciados e retornados ao sistema, pois, após cada participação, o usuário recebe toda uma série de estímulos que pode vir a compeli-lo a participar novamente, só que desta vez com novos valores adquiridos pelo sistema. Dessa forma, os processos envolvidos no desenrolar do tempo, a evolução do sistema, os procedimentos dinâmicos e as suas respostas não-previsíveis, a noção de feedback (realimentação positiva e negativa) possuem potencial para causar mudanças na receptividade dessa obra que ora emerge. Estaremos tratando de uma complexidade sistêmica, e não apenas daquela gerada por padrões randômicos, mas por um padrão que brota sem ter sido deliberadamente planejado. Esses padrões são observáveis por sua característica estrutural repetitiva. Não projetamos sistemas para criar deliberadamente essas estruturas, o que podemos fazer é criar condições para que isso aconteça, através de agentes independentes e algumas regras de interação ${ }^{40}$. Esses sistemas são animados, dinâmicos, fundados por iteratividade e mudam com o passar do tempo. Nesse trabalho, estaremos diante de estruturas e níveis de linguagens diferentes - matemática, lógica de programação, texto verbal e visual, diferentes línguas convivendo num mesmo espaço, subjetividades múltiplas e simultâneas a partir dos diferentes usuários participantes, telepresença e princípios de partilha de espaço e tempo, conectividade (operação em um ambiente de rede), ubiqüidade, a vazão do individual para o coletivo etc. -, e, portanto, não contamos apenas com a matemática para gerar tais padrões. Teríamos, assim, o conceito de emergência sendo utilizado poeticamente, resultado dos agentes locais interagindo através de suas regras de relacionamento. Note-se que há relações entre os elementos internos do sistema (interatividade endógena) e externos (interatividade exógena), pela participação e interação dos usuários, além do controle de realimentação positiva (pelos processos de filtragem, adiciona-se fator de adaptabilidade às palavras mais utilizadas, e isso provoca mudanças e movimentação no sistema) e negativa (o programa reduz a adaptabilidade das palavras, uma vez que estas deixem de ser reutilizadas durante um certo período de tempo, até o momento de retirá-las do ambiente tridimensional, com a intenção de normalizar a estabilidade e controle do sistema). Também relevante é que não temos controle das entradas das palavras adicionais, deixando dinâmico e aberto o banco de dados permanentemente. $\mathrm{E}$, finalmente, cabe dizer que esse trabalho fora proposto para atingir o propósito de experimentar sistemas dinâmicos e complexos, (quase) autônomos, multiusuários e interativos, através de derivações da geração de agentes, filtragem e padrões emergentes - conceitos que surgem no pensamento contemporâneo fundados pelos princípios originados pela cibernética de primeira e segunda ordem.
AMERICAN Society for cybernetics. Disponível em: http://www.asc cybernetics.org/index.htm. Acesso em: nov. de 2006.

CORDEIRO, Waldemar. Disponível em: http://www.visgraf.impa.br/ Gallery/waldemar/moscati/moscati.htm. Acesso em: nov. de 2006

COUCHOT, Edmond. A tecnologia na arte, da fotografia à realidade virtual. Porto Alegre: UFRGS Editora, 2003.

CRAMER, Florian. WORDS MADE FLESH - Code, Culture, Imagination. Media Design Research. Roterdã: Piet Zwart Institute/ Institute fo Postgraduate Studies and Research Willem de Kooning/ Academy Hogeschool, 2005. (Disponível em: http://www.pzwart.wdka.hro.nl.).

HOLLAND, John H. Adaptation in Natural and Artificial Systems. (1975). Cambridge, Massachusetts: The MIT Press, 2001. Emergence from Chaos to Order. Cambridge, Massachusetts: Perseus Publishing, 1998.

JAKOBSON, Roman. Linguiística e Comunicação. São Paulo: Cultrix, 1973.

LAURENTIZ, Paulo. A Holarquia do Pensamento Artístico. Campinas, SP: Ed. Unicamp, 1991.

MURRAY, Janet H. Hamlet on the Holodeck. The Future of Narrative in Cyberspace. Cambridge, Massachusetts: MIT Press, 2001.

PRADO, Gilbertto; LAURENTIZ, Silvia. Uma leitura poética de ambientes virtuais multiusuário. Revista Ars. ano 2, n. 3. São Paulo, Departamento de Artes Plásticas da ECA-USP, 2004.

STROGATZ, Steven. SYNC - The Emerging Science of Spontaneous Order. Theia, NY: Hyperion Books, 2003.

VENTURELLI, Suzete. Arte: espaço_tempo_imagem. $1^{\text {a }}$ ed. Brasília: Editora Universidade de Brasília, 2004.

WARDRIP-FRUIN, Noah; MONTFORT, Nick. The New Media Reader. Cambridge, Massachusetts: The MIT Press, 2003.

WIENER, Norbert. Cybernetics: or the control and communication in the animal and the machine. Cambridge, Massachusetts: The MIT Press, 1948. WILSON, Stephen. Information Arts. Intersections of Art, Science and Technology. Cambridge, Massachusetts: The MIT Press, 2002.
Não é um trabalho de rte, mas sua interface é interessante e

indicamos-nо сото ит bom exemplo de um

istema dinâmico e interativo do uso de palavras de um idioma.

39. Informações adi cionais sobre esses

processos podem ser encontradas no próprio site: www.e-gallery. com. br/cp/

40. Veja 'Teoria da Emergência' em JOHNSON, Steven (2001). Emergência. A vida integrada de formigas, cérebros, cidades e softwares. Rio de Janeiro: Jorge Zahar Editor, 2003. 